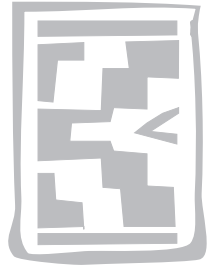

RESEARCH COMMUNICATION

\title{
A rapid and sensitive real-time reverse transcription PCR for the pathotyping of South African H5N2 avian influenza viruses
}

\author{
C. ABOLNIK \\ ARC-Onderstepoort Veterinary Institute, Private Bag X5, Onderstepoort, 0110 South Africa
}

\begin{abstract}
ABOLNIK, C. 2008. A rapid and sensitive real-time reverse transcription PCR for the pathotyping of South African H5N2 avian influenza viruses. Onderstepoort Journal of Veterinary Research, 75:347351

A Fluorescence resonance energy transfer (FRET) real-time reverse-transcription (rRT-PCR) assay was developed that distinguishes stains of South African and European highly pathogenic (HPAI) from low pathogenicity (LPAI) H5 avian influenza viruses in the absence of virus isolation, irrespective of the length of insertion at the hemagglutinin cleavage site $\left(\mathrm{H}_{0}\right)$. The assay was used to pathotype H5-type viruses detected by rRT-PCR in ostrich tracheal swabs collected during the 2006 HPAI H5N2 outbreak in the Western Cape Province.
\end{abstract}

Keywords: Avian influenza virus, H5N2, pathotyping, real-time reverse transcription PCR, FRET

\section{INTRODUCTION}

Highly pathogenic avian influenza (HPAl) is a devastating disease of poultry that has zoonotic potential for humans and is caused by strains of the $\mathrm{H} 5$ and $\mathrm{H} 7$ subtypes of influenza A viruses (family Orthomyxoviridae). The low pathogenicity avian influenza (LPAI) virus precursors to HPAl viruses are ubiquitous in wild waterfowl and shorebirds and usually only cause asymptomatic infections in these reservoir hosts. Once transferred to terrestrial poultry, LPAI viruses can convert into HPAI (Webster, Bean, Gorman, Chambers \& Kawaoka 1992).

Although the virulence determinants of avian influenza viruses are multigenic in nature, an insertion of multiple basic amino acids at the cleavage site of the haemagglutinin precursor protein, $\mathrm{H}_{0}$, targets this protein for cleavage by ubiquitous subtilisin-like endonucleases, resulting in rapid systemic spread of the virus. In contrast, LPAI viruses contain a

Accepted for publication 10 June 2008-Editor monobasic composition at $\mathrm{H}_{0}$ which is targeted by trypsin-like proteases that are limited to cells of the intestinal and respiratory tracts (Rott 1979; StienekeGröber, Vey, Angliker, Shaw, Thomas, Roberts, Klenk \& Garten 1992; Vey, Adler, Klenk, Rott \& Garten 1992; Wood, McCauley, Bashiruddin \& Alexander 1993). The amino acid sequence at $H_{0}$ is thus recognized as an important and reliable molecular virulence marker (OIE Terrestrial Manual 2004).

South Africa was affected by two separate outbreaks of HPAI H5N2 in intensively-farmed ostriches between 2004 and 2006, and intensive serological and virological surveillance was conducted during both outbreaks. Of thousands of tracheal swabs or organ samples tested, 46 were positive or suspect positive for the presence of AIV by real-time reverse transcription-PCR (rRT-PCR) or nucleic acid-based sequence assay (NASBA) (M. Romito, unpublished laboratory data). H5-type viruses were isolated in only $3(6.5 \%)$ of these cases, viz. the HPAI H5N2 virus isolated in the Eastern Cape outbreak in 2004 (OSZA04N227), the HPAI H5N2 virus isolated in 
the Western Cape outbreak of2006(OSZA06AI1091) and the LPAI H5N2 virus isolated in the same outbreak (OSZA06Al1160). The isolate OSZA06Al1091 contained fewer multiple basic amino acids at $\mathrm{H}_{0}$ than did isolate OSZA04N227, but was clearly HPAI according to the OIE definition (Abolnik 2007b). Unfortunately however, the nucleic acids detected by $\mathrm{rRT}-\mathrm{PCR} / \mathrm{NASBA}$ are present in insufficient quantities to allow further molecular characterization (Hoffmann, Starick, Depner, Werner \& Beer 2007; unpublished laboratory data 2007), yet for control purposes there is an urgent need to be able to differentiate between LPAI and HPAI viruses in ostriches especially where virus isolation has not been successful. At least two other groups have described sensitive rRT-PCR assays for HPAI H5 pathotyping, hoewever the SYBR Green method described by Payungporn, Chutinimitkul, Chaisingh, Damrongwantanapokin, Nuansrichay, Pinyochon, Amonsin, Donis, Theamboonlers \& Poovorawan (2006) may give false positive results (Fernández, Gutierrez, Sorlozano, Romero, Soto \& Ruiz-Cabello 2006). In the method of Hoffmann and co-workers (2007), a set of hydrolysis probes was described that detects the Asian group of HPAI H5N1, and the $\mathrm{H}_{0}$ cleavage site sequence of the Qinghai strain in particular. However, insertions/substitutions in the $\mathrm{H}_{0}$ cleavage site abolished signal generation. As demonstrated for isolates from in South Africa (Fig. 1), potential variations in the $\mathrm{H}_{0}$ cleavage site sequence need to be taken into account. Therefore a rapid and sensitive rRT-PCR assay was developed to distinguish between South African HPAI and LPAI $\mathrm{H} 5 \mathrm{~N} 2$ viruses in the absence of virus isolation that does not rely on the sequence at $\mathrm{H}_{0}$.

\section{MATERIALS AND METHODS}

\section{Primer and probe design}

A set of primers (InfA_H5_F and InfA_H5_R) and three probes (InfA_H5_640, InfA_H5_FL and InfA_ H5_705) were designed for the amplification and detection of a fragment spanning the cleavage site sequence of the H5N2 HA gene (Table 1). The LCRed640 fluorophore-labelled InfA_H5_640 probe was designed to hybridize over the consensus LPAI sequence that is conserved within the $\mathrm{H} 5$ lineage. The InfA_H5_FL binds a sequence adjacent to this, and is labelled at both the 5' and 3' ends with fluorescein. The LCRed705 fluorophore-labelled InfA_H5_ 705 probe binds at the opposite end of InfA_H5_FL, in a conserved region within the $\mathrm{H} 5$ sub-lineage. In the presence of an LPAI sequence, the three probes will bind in tandem and both acceptor probes will be excited by the flourescein donor probe, resulting in

TABLE 1 Primers and probes used to differentiate between HPAI and LPAI in this study ${ }^{\mathrm{a}}$

\begin{tabular}{|l|l|l|}
\hline Primer/probe & Sequence (5'-3'), -fluorophore & Nucleotide position (Fig. 1) \\
\hline InfA_H5_F & GTGCCCCAAATACGTGAARTCA & $951-972$ \\
InfA_H5_R & CCATCTATTGCTTKKTGAGTGGACTC & $1169-1143$ \\
InfA_H5_640 & 640-TCCTCTTGTTTCTYTTTGAGGGACATT-p & $1029-1067$ \\
InfA_H5_FL & F-CCTCCTTCTATAAARCCTGCTATRGCCCCAAATA-F & $1069-1102$ \\
InfA_H5_705 & -pCCATACCAACCRTCTACCATKCCTTGCC-705 & $1105-1133$ \\
\hline
\end{tabular}

a Primers and probes were designed in collaboration with and manufactured by TIB MOLBIOL, Eresburgstr. 22-23, D-12103 Berlin, Germany

TABLE 2 Results of the H5 rRT-PCR pathotyping assay

\begin{tabular}{|l|l|l|l|l|}
\hline \multicolumn{2}{|l|}{ Sample } & F2 $_{(640)}$ Cp & F3 $_{(705)}$ Cp & Pathotype \\
\hline $\mathrm{dH}_{2}$ 0 & Negative control & - & - & - \\
OSZA06Al1091 $_{\text {OSZA06Al1160 }}$ & HPAl positive control & - & 22.34 & $\mathrm{HPAl}$ \\
Al1133.1 & LPAl positive control & 20.46 & 20.59 & LPAl \\
Al1133.11 & Ostrich tracheal swab & - & - & - \\
Al1133.12 & Ostrich tracheal swab & - & 29.90 & HPAl \\
Al1133.13 & Ostrich tracheal swab & 26.34 & 26.21 & LPAl \\
Al1133.15 & Ostrich tracheal swab & - & 28.83 & HPAl \\
Al1133.16 & Ostrich tracheal swab & - & 31.12 & - \\
Al1133.17 & Ostrich tracheal swab & - & - & - \\
Al1133.23 & Ostrich tracheal swab & - & - & - \\
Al1120.37 & Ostrich tracheal swab & - & - & HPAI \\
Al1149.6 & Ostrich tracheal swab & - & 29.80 & - \\
\hline
\end{tabular}




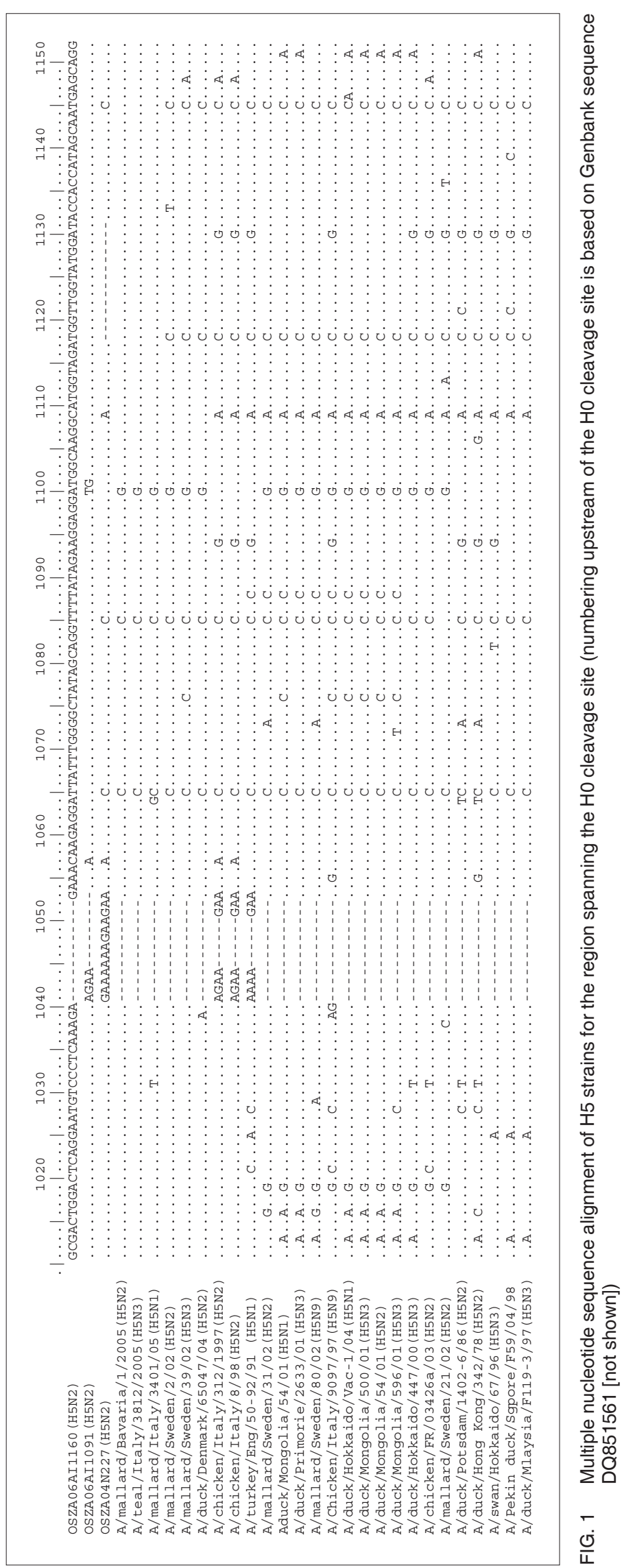


two signals that are detectable at different wavelengths (LightCycler ${ }^{\circledR}$ channels F2 and F3). The presence of insertions or substitutions in the $\mathrm{H}_{0}$ cleavage site of HPAl virus will however abolish the binding of InfA_H5_640 and only one signal in channel F3 would thus be visible.

\section{RNA extraction and first-strand cDNA synthesis}

Viral RNA was extracted from tracheal swabs or infective allantoic fluid with a Total Nucleic Acid Isolation kit (Roche) using a MagNALyser and TRIzo|® LS Reagent (Gibco, Invitrogen), respectively. Firststrand cDNA synthesis was accomplished by incubating $5 \mu \ell$ RNA, $2 \mu \ell$ random hexamer and $6 \mu \ell$ $\mathrm{dH}_{2} \mathrm{O}$ at $65^{\circ} \mathrm{C}$ for $10 \mathrm{~min}$. After snap-cooling in an ice bath for $5 \mathrm{~min}, 4 \mu \ell$ of $5 \mathrm{X}$ RT buffer, $0.5 \mu \ell$ of RNAse inhibitor, $2 \mu \ell 10 \mathrm{mM}$ dNTPs and $0.5 \mu \ell$ Transcriptor Reverse Transcriptase ${ }^{\circledR}$ (Roche) were added. The reactions were incubated at $55^{\circ} \mathrm{C}$ for $30 \mathrm{~min}$.

\section{rRT-PCR}

A LightCycler® FastStart DNA Master ${ }^{\text {PLUS }}$ HybProbe kit (Roche) and LightCycler ${ }^{\circledR} 2.0$ device were utilized for real-time PCR using $5 \mu \ell$ of the cDNA in a total volume of $20 \mu \ell$. The temperature profile was used as follows: $10 \mathrm{~min}$ at $94^{\circ} \mathrm{C}$, and 45 cycles of $20 \mathrm{~s}$ at $95^{\circ} \mathrm{C}, 15 \mathrm{~s}$ at $55^{\circ} \mathrm{C}$, and $20 \mathrm{~s}$ at $72^{\circ} \mathrm{C}$. Fluorophore-specific emission data were collected during the annealing step. Crossing point $(\mathrm{Cp})$ values were calculated with LightCycler 3.5 software using the second derivative maximum method. The assay was applied to ten samples from the recent outbreaks in 2006 that were positive or suspect positive for the presence of $\mathrm{H} 5$ virus by rRT-PCR during surveillance but where virus isolation was unsuccessful (Table 2).

\section{RESULTS AND DISCUSSION}

The positive controls, OSZA061160 (LPAI) and OSZA06Al1091 (HPAI), produced fluorescent signals in both and in one channel, respectively (Table 2). Unknown samples Al1133.11, Al1133.13, Al1133.15 and Al1120.37 were HPAl positive, whereas Al1133.12 was LPAI positive. Five of the samples gave negative results, which may have been due to RNA degradation during prolonged storage. Interestingly, LPAI and HPAI were detected within the same flock (Al1133 samples). OSZA04N227 (HPAI, 2004) did not amplify, due to an unusual sequence deletion detected between nucleotides 1121 and 1134 (Fig. 1) (Abolnik 2007a). (The assay has been adapted for high throughput on the LightCycler480® system by replacing the LCRed710 fluorophore with an LCRed610 fluorophore, and use of a one-step RT-PCR kit).

In South Africa the reemergence of H5N2 in poultry is a constant threat because the LPAI strain exists in the wild bird reservoir (Abolnik 2007b) but this particular LPAI H5N2 lineage is also circulating in the European wild waterfowl population (Abolnik 2007a) and therefore after further validation the primer and probe set described here could be used in Europe since poultry in that region is also at risk of infection and consequent mutation. I have described here a rapid and sensitive method to pathotype $\mathrm{H} 5$-positive swabs where virus isolation has been unsuccessful. This approach of detecting the consensus LPAI $\mathrm{H}_{0}$ sequence with abolishment of binding as an indicator of the presence of an HPAI strain (provided that adjacent or upstream controls are included) could be adapted for the pathotyping of other lineages of AIV H5 and extended to hydrolysis probe chemistries.

\section{ACKNOWLEDGEMENTS}

I thank Hans-Henno Dorries for assisting with primer/ probe design, Rachel Maluleke and Bontsi MarumoMochothloane for technical assistance, and Truuske Gerdes and Marco Romito for useful discussions.

\section{REFERENCES}

ABOLNIK, C. 2007a. Molecular epidemiology of Newcastle disease and avian influenza in South Africa. Ph.D. thesis. University of Pretoria, South Africa. http://upetd.up.ac.za/UPeTD.htm.

ABOLNIK, C. 2007b. Molecular characterization of H5N2 avian influenza viruses isolated from South African ostriches in 2006. Avian Diseases, 51:873-879.

FERNANDEZ, GUTIERREZ, F.J., SORLOZANO, A., ROMERO, J.M., SOTO, M.J. \& RUIZ-CABELLO, F. 2006. Comparison of the SYBR Green and the hybridization probe format for real-time PCR detection of HHV-6. Microbiology Research, 161:158-163.

HOFFMANN, B., HARDER, T., STARICK, E., DEPNER, K., WERNER, O. \& BEER, M. 2007. Rapid and highly sensitive pathotyping of avian influenza A H5N1 virus using real-time RT-PCR. Journal of Clinical Microbiology, 45:600-603.

OIE TERRESTRIAL MANUAL 2004. Highly pathogenic avian influenza. Paris: Office International des Epizooties.

PAYUNGPORN, S., CHUTINIMITKUL, S., CHAISINGH, A., DAMRONGWANTANAPOKIN, S., NUANSRICHAY, B., PINYOCHON, W., AMONSIN, A., DONIS, R.O., THEAMBOONLERS, A. \& POOVORAWAN, Y. 2006. Discrimination between highly pathogenic and low pathogenic $\mathrm{H} 5$ avian influenza $\mathrm{A}$ viruses. Emerging Infectious Diseases, 12:700-701. 
ROTT, R. 1979. Molecular basis of infectivity and pathogenicity of myxoviruses. Archives of Virology, 59:285-298.

STIENEKE-GRÖBER, A., VEY, M., ANGLIKER, H., SHAW, E., THOMAS, G., ROBERTS, C., KLENK, H-D. \& GARTEN, W. 1992. Influenza virus hemagglutinin with multibasic cleavage site is activated by furin, a subtilisin endoprotease. EMBO Journal, 11:2407-2414.

VEY, M., ORLICH, M., ADLER, S., KLENK, H-D., ROTT, R. \& GARTEN, W. 1992. Haemagglutinin activation of pathogenic avian influenza viruses of serotype $\mathrm{H} 7$ requires the recognition motif R-X-R/K-R. Virology, 188:408-413.

WEBSTER, R.G., BEAN, W.J., GORMAN, O.T., CHAMBERS, T.M. \& KAWAOKA, Y. 1992. Evolution and ecology of influenza A viruses. Microbiology Reviews, 56:152-179.

WOOD, G.W., MCCAULEY, J.W., BASHIRUDDIN, J.B. \& ALEXANDER, D.J. 1993. Deduced amino acid sequences at the haemagglutinin cleavage site of avian influenza $A$ viruses of H5 and H7 subtypes. Archives of Virology, 130:209-217. 